\title{
АНАЛИЗ УРОВНЯ БЛАГОСОСТОЯНИЯ В ЗАБАЙКАЛЬСКОМ КРАЕ
}

\begin{abstract}
АННОтАЦИЯ. Формирование благосостояния региона в статье описывается с позиций процессов, протекающих в экономической и социальной сферах и нацеленных на удовлетворение наиболее важных потребностей населения. С точки зрения потребностей данные процессы представляют собой факторы, обусловливающие степень их удовлетворения. На примере Забайкальского края показано, что данные факторы оказывают как положительное, так и отрицательное влияние на уровень удовлетворения потребностей и, таким образом, обусловливают уровень регионального благосостояния, которое рассматривается как совокупность благ, обеспечивающих необходимые условия для жизнедеятельности и развития населения. Анализ основных процессов, нацеленных на формирование благосостояния в Забайкальском крае, позволил оценить влияние экономических и социальных процессов на уровень регионального благосостояния, определить характер данного влияния, выявить «проблемные зоны» и «зоны относительного благополучия», которые необходимо учитывать при разработке стратегий и программ социального экономического региона. Кроме этого, в работе также представлен анализ динамики интегрального показателя уровня регионального благосостояния.
\end{abstract}

кЛючЕВЫЕ СЛОВА. Уровень благосостояния; результативность процессов потребности населения; экономическое благосостояние; социальное благосостояние.

ИНФОРМАЦИЯ О СТАТЬЕ. Дата поступления 6 апреля 2016 г.; дата принятия к печати 29 апреля 2016 г.; дата онлайн-размещения 25 июля 2016 г.

L. B. Kovalchuk

Baikal State University, Chita, Russian Federation

\section{ANALYSIS OF WELFARE LEVEL IN ZABAIKALSKY TERRITORY}

ABSTRACT. The article describes development of the region's welfare from the perspective of the processes taking place in economic and social spheres and aimed at meeting the most important demands of the population. From the point of view of the demands, these processes are the factors that determine the degree of their accomplishment. The example of Zabaikalsky Territory shows that these factors exercise both positive and negative impacts on satisfaction of needs and, thus, determine the level of regional welfare which is considered as an aggregate of the benefits that provide the necessary conditions for vital activities and development of the population. Analysis of the major processes aimed at developing welfare in Zabaikalsky Territory allows to assess the impact of the economic and social; processes on the level of the regional welfare, to determine the character of this impact, to identify «the problematic zones» and «zones of relative welfare» which must be considered in developing the strategies and programs of the social and economic region. Besides, the paper presents an analysis of dynamics for the integral indicator of the regional welfare level.

KEYWORDS. Welfare level; efficiency of public needs process; economic welfare; social welfare.

ARTICLE INFO. Received April 6, 2016; accepted April 29, 2016; available online July 25, 2016.

Достижение высокого уровня благосостояния в регионе зависит от результативности процессов, протекающих в экономической и социальной сферах региона [1-9]. Для определения тенденций и направлений социально-экономического

() Л. Б. Ковальчук, 2016

\section{Baikal Research Journal}

электронный научный журнал Байкальского государственного университета 
развития, а также своевременного выявления проблем необходима диагностика общих результатов данных процессов, которая может быть осуществлена на основе анализа динамики результативности интегрального экономического и социального процессов. Интегральный показатель результативности всех экономических процессов интерпретируется нами как уровень экономического благосостояния населения региона. Интегральный показатель результативности социальных процессов - соответственно, всех социальных процессов. Интегральная оценка результативности экономических и социальных процессов может быть получена в результате свертки показателей результативности процессов, нацеленных на удовлетворение определенных материальных и нематериальных потребностей населения региона. Свертка показателей результативности данных процессов выполнялась на основе нечеткого логического вывода с помощью компьютерной экспертной системы, построенной в пакете MATLAB.

Учитывая, что показатели результативности процессов, входящих в состав совокупного регионального процесса, имеют разную размерность, для их оценки использовалась единая шкала термов: Н - низкий, С - средний, В - высокий. Каждый из данных термов представляет собой нечеткое множество, заданное с помощью соответствующей функции принадлежности $\mu A(x)$, принимающей значения на множестве $M=[0,1]$. При этом все «четкие» показатели результативности региональных процессов, в качестве которых использовались статистические показатели, были приведены к единому универсальному интервалу, который соответствовал отрезку числовой прямой [0;10]. На данном универсальном интервале 0 - наименьшее значение результативности процесса, 10 - максимальное значение результативности процесса. Анализ уровня благосостояния в Забайкальском крае осуществлялся на горизонте с 2004 по 2014 г. В периоде исследования экономическое благосостояние в Забайкальском крае формировалось на основе результативности процессов, которые в период с 2004 по 2014 г. отличалась нестабильностью: результативность процессов менялась от низкой к высокой (табл. 1). Имели место значительные волнообразные флуктуации результативности региональных процессов, отличающиеся частотой, диапазоном и продолжительностью изменений. Высокий уровень флуктуаций позволяет сделать вывод об отсутствии в крае адекватной стратегии социально- экономического развития и о концентрации управленческих воздействий на ликвидацию текущих проблем в экономике.

Исследование результативности региональных экономических процессов показало, что на протяжении 10 лет в Забайкальском крае крайне неустойчивыми были следующие процессы: сельскохозяйственное производство, производство продукции пищевой промышленности, добыча полезных ископаемых, производство и распределение электроэнергии, газа, воды, производство продукции обрабатывающих производств, т. е. процессы, необходимые для производства благ, удовлетворяющих основные материальные потребности населения. Причиной неустойчивости данных процессов может быть низкий уровень результативности процессов, рассеивающих ресурсы региональной системы, а именно: износ основных фондов, рост цен на рынке жилья, загрязнение атмосферного воздуха, бюрократизация. Влияние данных процессов заключается в формировании барьеров для производства и потребления необходимых благ в форме изношенных основных фондов, неэффективного производства и низкой конкурентоспособности видов экономической деятельности. Динамика и результативность процессов, протекающих в экономике Забайкальского края, обусловили уровень результативности интегрального экономического процесса. Представим его оценку с помощью нечетких значений: низкий, средний, высокий (табл. 2).

\section{Baikal Research Journal}

электронный научный журнал Байкальского государственного университета 
Таблица 1

Нечеткие значения показателей результативности эконолических процессов Забайкальского края

\begin{tabular}{|c|c|c|c|c|c|c|c|c|c|c|c|}
\hline Процесс & 2004 & 2005 & 2006 & 2007 & 2008 & 2009 & 2010 & 2011 & 2012 & 2013 & 2014 \\
\hline $\begin{array}{l}\text { Сельскохозяйственное про- } \\
\text { изводство }\end{array}$ & $\mathrm{H}$ & $\mathrm{H}$ & $\mathrm{H}$ & $\mathrm{H}$ & $\mathrm{C}$ & $\mathrm{C}$ & $\mathrm{C}$ & B & B & B & $\mathrm{B}$ \\
\hline $\begin{array}{l}\text { Производство продукции } \\
\text { пищевой промышленности }\end{array}$ & $\mathrm{B}$ & B & B & B & $\mathrm{H}$ & $\mathrm{H}$ & $\mathrm{B}$ & $\mathrm{B}$ & B & $\mathrm{C}$ & B \\
\hline Услуги розничной торговли & $\mathrm{B}$ & $\mathrm{B}$ & $\mathrm{B}$ & $\mathrm{B}$ & $\mathrm{C}$ & $\mathrm{H}$ & $\mathrm{B}$ & $\mathrm{B}$ & $\mathrm{C}$ & $\mathrm{C}$ & B \\
\hline $\begin{array}{l}\text { Деградация сельскохозяй- } \\
\text { ственных земель }\end{array}$ & $\mathrm{C}$ & B & $\mathrm{H}$ & $\mathrm{H}$ & $\mathrm{C}$ & $\mathrm{C}$ & B & $\mathrm{B}$ & B & B & $\mathrm{H}$ \\
\hline Рост цен на продовольствие & $\mathrm{C}$ & $\mathrm{C}$ & $\mathrm{B}$ & $\mathrm{H}$ & $\mathrm{H}$ & $\mathrm{B}$ & $\mathrm{C}$ & $\mathrm{C}$ & $\mathrm{B}$ & $\mathrm{C}$ & $\mathrm{H}$ \\
\hline Строительство жилья & $\mathrm{H}$ & $\mathrm{H}$ & $\mathrm{H}$ & $\mathrm{B}$ & $\mathrm{B}$ & $\mathrm{B}$ & $\mathrm{B}$ & $\mathrm{B}$ & $\mathrm{B}$ & $\mathrm{B}$ & $\mathrm{C}$ \\
\hline $\begin{array}{l}\text { Улучшение жилищных } \\
\text { условий }\end{array}$ & $\mathrm{H}$ & $\mathrm{H}$ & $\mathrm{H}$ & $\mathrm{C}$ & $\mathrm{C}$ & $\mathrm{B}$ & $\mathrm{B}$ & $\mathrm{B}$ & $\mathrm{B}$ & $\mathrm{B}$ & $\mathrm{H}$ \\
\hline Рост цен на жилье & $\mathrm{H}$ & $\mathrm{H}$ & $\mathrm{C}$ & $\mathrm{B}$ & $\mathrm{C}$ & $\mathrm{C}$ & $\mathrm{H}$ & $\mathrm{H}$ & $\mathrm{H}$ & $\mathrm{H}$ & $\mathrm{B}$ \\
\hline $\begin{array}{l}\text { Рост цен на услуги жилищ- } \\
\text { но-коммунального ком- } \\
\text { плекса }\end{array}$ & $\mathrm{C}$ & $\mathrm{C}$ & $\mathrm{B}$ & B & $\mathrm{C}$ & $\mathrm{H}$ & $\mathrm{B}$ & $\mathrm{B}$ & $\mathrm{B}$ & $\mathrm{B}$ & B \\
\hline $\begin{array}{l}\text { Модернизация производ- } \\
\text { ства }\end{array}$ & $\mathrm{H}$ & $\mathrm{H}$ & $\mathrm{H}$ & $\mathrm{C}$ & $\mathrm{C}$ & $\mathrm{C}$ & B & $\mathrm{C}$ & $\mathrm{C}$ & B & $\mathrm{H}$ \\
\hline Инновационный процесс & $\mathrm{H}$ & $\mathrm{H}$ & $\mathrm{H}$ & $\mathrm{H}$ & $\mathrm{H}$ & $\mathrm{H}$ & $\mathrm{H}$ & $\mathrm{B}$ & $\mathrm{B}$ & $\mathrm{H}$ & $\mathrm{H}$ \\
\hline $\begin{array}{l}\text { Рост цен на промышленные } \\
\text { товары }\end{array}$ & $\mathrm{C}$ & $\mathrm{C}$ & $\mathrm{B}$ & $\mathrm{B}$ & $\mathrm{C}$ & $\mathrm{H}$ & $\mathrm{B}$ & $\mathrm{B}$ & B & $\mathrm{B}$ & $\mathrm{B}$ \\
\hline Бюрократизация & $\mathrm{B}$ & $\mathrm{B}$ & $\mathrm{B}$ & $\mathrm{H}$ & $\mathrm{H}$ & $\mathrm{H}$ & $\mathrm{H}$ & $\mathrm{H}$ & $\mathrm{H}$ & $\mathrm{H}$ & $\mathrm{H}$ \\
\hline $\begin{array}{l}\text { Добыча полезных иско- } \\
\text { паемых }\end{array}$ & $\mathrm{H}$ & $\mathrm{C}$ & $\mathrm{H}$ & $\mathrm{C}$ & $\mathrm{H}$ & $\mathrm{H}$ & $\mathrm{B}$ & B & $\mathrm{H}$ & $\mathrm{B}$ & $\mathrm{H}$ \\
\hline $\begin{array}{l}\text { Производство продукции } \\
\text { обрабатывающих отраслей }\end{array}$ & $\mathrm{C}$ & B & $\mathrm{B}$ & B & $\mathrm{C}$ & $\mathrm{H}$ & B & $\mathrm{C}$ & $\mathrm{B}$ & B & $\mathrm{H}$ \\
\hline $\begin{array}{l}\text { Производство и распределе- } \\
\text { ние электроэнергии, воды, } \\
\text { газа }\end{array}$ & $\mathrm{H}$ & $\mathrm{H}$ & $\mathrm{H}$ & $\mathrm{H}$ & $\mathrm{H}$ & $\mathrm{H}$ & $\mathrm{C}$ & B & B & $\mathrm{B}$ & $\mathrm{H}$ \\
\hline Износ основных средств & $\mathrm{H}$ & $\mathrm{H}$ & $\mathrm{H}$ & $\mathrm{H}$ & $\mathrm{H}$ & $\mathrm{C}$ & $\mathrm{C}$ & $\mathrm{H}$ & $\mathrm{H}$ & $\mathrm{H}$ & $\mathrm{B}$ \\
\hline $\begin{array}{l}\text { Загрязнение атмосферного } \\
\text { воздуха выбросами, исхо- } \\
\text { дящими от стационарных } \\
\text { источников }\end{array}$ & B & B & $\mathrm{H}$ & $\mathrm{H}$ & $\mathrm{H}$ & $\mathrm{H}$ & $\mathrm{H}$ & $\mathrm{H}$ & $\mathrm{H}$ & $\mathrm{H}$ & $\mathrm{C}$ \\
\hline Услуги транспорта & $\mathrm{H}$ & $\mathrm{H}$ & $\mathrm{B}$ & $\mathrm{B}$ & $\mathrm{B}$ & $\mathrm{B}$ & $\mathrm{B}$ & $\mathrm{B}$ & $\mathrm{B}$ & $\mathrm{B}$ & $\mathrm{B}$ \\
\hline $\begin{array}{l}\text { Дорожно-транспортные } \\
\text { происшествия }\end{array}$ & B & $\mathrm{C}$ & $\mathrm{C}$ & $\mathrm{H}$ & $\mathrm{H}$ & B & $\mathrm{C}$ & B & $\mathrm{B}$ & B & $\mathrm{B}$ \\
\hline
\end{tabular}

Н - низкая результативность; С - средняя результативность; В - высокая результативность.

Таблица 2

\section{Уровень экономического благосостояния в Забайкальскол крае,} выраженный нечеткими значениями, в 2004-2014 22.

\begin{tabular}{|l|c|c|c|c|c|c|c|c|c|c|c|} 
Показатель & 2004 & 2005 & 2006 & 2007 & 2008 & 2009 & 2010 & 2011 & 2012 & 2013 & 2014 \\
\hline
\end{tabular} \begin{tabular}{|l|l|l|l|l|l|l|l|l|l|l|l|}
\hline Результативность интегрально- & C & H & C & C & C & C & C & C & C & C & C \\
\hline
\end{tabular} го экономического процесса

$\mathrm{H}$ - низкий уровень; $\mathrm{C}$ - средний уровень; В - высокий уровень.

Отметим, что интегральная результативность экономических процессов в Забайкальском крае на протяжении целого десятилетия не изменялась и оставалась на среднем уровне, что является показателем застоя в экономике, который обу-

\section{Baikal Research Journal}


словливает застой в уровне экономического благосостояния, не удовлетворяет население региона, что выражается в высоких показателях миграции, сохранении стабильно высокого отрицательного сальдо миграционного оттока. Сохранение на протяжении десятилетия среднего уровня экономического благосостояния означает, что в экономической сфере создается недостаточное количество ресурсов и благ, необходимых для удовлетворения растущих потребностей населения, в том числе и нематериальных.

Для того чтобы оценить уровень удовлетворения нематериальных потребностей, необходимо представить интегральную оценку результативности процессов, протекающих в социальной сфере региона. Для оценки выберем процессы, связанные с удовлетворением наиболее важных потребностей населения, образующих важную нематериальную основу жизнедеятельности и интеллектуально-нравственного развития человека, общества. $К$ числу данных потребностей в целях исследования нами были отнесены: потребность в труде, физическом здоровье, общекультурных компетенциях, информации, культуре. Их воплощению в жизнь должны способствовать следующие социальные процессы: создание сети больниц и поликлинических учреждений, обновление основных фондов учреждений социальной сферы, создание сети дошкольных и образовательных учреждений, обновление основных фондов учреждений образования, социокультурное развитие, использование информационно-коммуникационных технологий.

Динамика результативности процессов, протекающих в социальной сфере Забайкальского края, выраженная нечеткими значениями, свидетельствует об их нелинейном характере (табл. 3). Отмечаются достаточно резкие изменения результативности таких процессов, как «создание сети больничных и поликлинических учреждений», «создание сети дошкольных учреждений», «обновление основных фондов образовательных учреждений». При этом очевидно, что изменения результативности представленных процессов нельзя рассматривать как признак планомерного социального развития и повышения уровня социального благосостояния. Обновление основных фондов, строительство больниц и поликлинических учреждений в крае связано, прежде всего, с расширением объема платных медицинских и образовательных услуг и, на фоне снижения доходов населения, сокращения общего материального благосостояния в регионе может формировать предпосылки регресса в социальной сфере. При этом в крае складываются отрицательные предпосылки для социального развития: снижение результативности процессов социокультурного развития, использования информационных-телекоммуникационных технологий, развития предпринимательства. Данные процессы, с нашей точки зрения, создают интеллектуально-технологическую основу для социального развития и перспективного повышения уровня социального благосостояния населения края.

В целом, процессы, протекающие в социальной сфере, демонстрируют низкий и средний уровень результативности, что означает, что повышение уровня социального благосостояния населения не входит в число приоритетов социально-экономического развития Забайкальского края. При этом уровень результативности процессов, динамика которых положительна, достигает, в основном, среднего уровня. Значения «высокий» отмечают уровень результативности процессов спорадически, что свидетельствует о том, что рост результативности является следствием решения отдельных проблем.

Процессы, протекающие в социальной сфере, формируют уровень социального благосостояния в крае. Интегральная оценка данных процессов, демонстрирующая уровень социального благосостояния, выраженная нечеткими значениями, представлена в табл. 4.

\section{Baikal Research Journal}

электронный научный журнал Байкальского государственного университета 
Таблица 3

Диналика процессов, протекающих в социальной сфере Забайкальского края, представленная нечеткими значенияли, в 2004-2014 22.

\begin{tabular}{|c|c|c|c|c|c|c|c|c|c|c|c|}
\hline Процесс & 2004 & 2005 & 2006 & 2007 & 2008 & 2009 & 2010 & 2011 & 2012 & 2013 & 2014 \\
\hline Предпринимательство & B & B & $\mathrm{H}$ & $\mathrm{H}$ & $\mathrm{H}$ & $\mathrm{H}$ & $\mathrm{C}$ & $\mathrm{C}$ & $\mathrm{H}$ & $\mathrm{H}$ & B \\
\hline $\begin{array}{l}\text { Маргинализация насе- } \\
\text { ления }\end{array}$ & $\mathrm{C}$ & $\mathrm{C}$ & $\mathrm{H}$ & $\mathrm{H}$ & B & $\mathrm{C}$ & $\mathrm{H}$ & $\mathrm{H}$ & $\mathrm{H}$ & $\mathrm{H}$ & $\mathrm{C}$ \\
\hline Создание сети больниц & $\mathrm{H}$ & $\mathrm{H}$ & $\mathrm{C}$ & $\mathrm{C}$ & $\mathrm{C}$ & $\mathrm{H}$ & $\mathrm{H}$ & $\mathrm{C}$ & $\mathrm{B}$ & $\mathrm{B}$ & B \\
\hline $\begin{array}{l}\text { Создание сети поликли- } \\
\text { нических учреждений }\end{array}$ & $\mathrm{H}$ & $\mathrm{C}$ & $\mathrm{C}$ & B & $\mathrm{H}$ & $\mathrm{B}$ & $\mathrm{B}$ & $\mathrm{H}$ & $\mathrm{H}$ & $\mathrm{H}$ & $\mathrm{H}$ \\
\hline $\begin{array}{l}\text { Обновление основных } \\
\text { фондов учреждений со- } \\
\text { циальной сферы }\end{array}$ & $\mathrm{H}$ & $\mathrm{C}$ & $\mathrm{C}$ & $\mathrm{C}$ & $\mathrm{C}$ & $\mathrm{C}$ & $\mathrm{H}$ & B & $\mathrm{C}$ & B & B \\
\hline Пауперизация населения & B & B & $\mathrm{C}$ & $\mathrm{C}$ & $\mathrm{H}$ & $\mathrm{H}$ & $\mathrm{H}$ & $\mathrm{H}$ & $\mathrm{H}$ & $\mathrm{H}$ & $\mathrm{H}$ \\
\hline $\begin{array}{l}\text { Создание сети дошколь- } \\
\text { ных учреждений }\end{array}$ & $\mathrm{H}$ & $\mathrm{H}$ & $\mathrm{C}$ & B & $\mathrm{C}$ & $\mathrm{C}$ & $\mathrm{H}$ & $\mathrm{H}$ & $\mathrm{H}$ & B & B \\
\hline $\begin{array}{l}\text { Создание сети образова- } \\
\text { тельных учреждений }\end{array}$ & $\mathrm{H}$ & $\mathrm{H}$ & B & $\mathrm{B}$ & $\mathrm{H}$ & B & $\mathrm{H}$ & $\mathrm{H}$ & $\mathrm{H}$ & $\mathrm{C}$ & $\mathrm{H}$ \\
\hline $\begin{array}{l}\text { Обновление основных } \\
\text { фондов образовательных } \\
\text { учреждений }\end{array}$ & $\mathrm{H}$ & $\mathrm{C}$ & $\mathrm{C}$ & $\mathrm{C}$ & $\mathrm{C}$ & $\mathrm{C}$ & $\mathrm{H}$ & $\mathrm{B}$ & $\mathrm{C}$ & B & $\mathrm{H}$ \\
\hline $\begin{array}{l}\text { Ухудшение условий } \\
\text { обучения }\end{array}$ & B & B & $\mathrm{H}$ & $\mathrm{H}$ & $\mathrm{H}$ & $\mathrm{H}$ & $\mathrm{H}$ & $\mathrm{H}$ & $\mathrm{C}$ & $\mathrm{H}$ & $\mathrm{H}$ \\
\hline $\begin{array}{l}\text { Социокультурное раз- } \\
\text { витие }\end{array}$ & $\mathrm{H}$ & $\mathrm{C}$ & $\mathrm{H}$ & $\mathrm{H}$ & $\mathrm{H}$ & B & $\mathrm{H}$ & $\mathrm{H}$ & $\mathrm{H}$ & $\mathrm{H}$ & $\mathrm{H}$ \\
\hline $\begin{array}{l}\text { Социокультурная дегра- } \\
\text { дация }\end{array}$ & $\mathrm{H}$ & $\mathrm{H}$ & $\mathrm{H}$ & $\mathrm{C}$ & $\mathrm{C}$ & B & B & B & B & B & B \\
\hline $\begin{array}{l}\text { Криминализация насе- } \\
\text { ления }\end{array}$ & B & B & B & B & B & B & B & B & B & $\mathrm{H}$ & $\mathrm{C}$ \\
\hline $\begin{array}{l}\text { Использование информа- } \\
\text { ционно-коммуникацион- } \\
\text { ных технологий }\end{array}$ & B & B & $\mathrm{H}$ & $\mathrm{H}$ & $\mathrm{H}$ & B & $\mathrm{C}$ & $\mathrm{H}$ & $\mathrm{H}$ & $\mathrm{H}$ & $\mathrm{H}$ \\
\hline $\begin{array}{l}\text { Удорожание информа- } \\
\text { ционно-коммуникацион- } \\
\text { ных технологий }\end{array}$ & $\mathrm{H}$ & $\mathrm{H}$ & $\mathrm{H}$ & $\mathrm{H}$ & $\mathrm{H}$ & $\mathrm{H}$ & $\mathrm{H}$ & $\mathrm{H}$ & $\mathrm{H}$ & $\mathrm{H}$ & B \\
\hline
\end{tabular}

Н - низкая результативность; С - средняя результативность; В - высокая результативность.

Уровень сочиального благосостояния в Забайкальскол крае,

Таблица 4 представленный нечеткили значенияли, в 2004-2014 22.

\begin{tabular}{|l|c|c|c|c|c|c|c|c|c|c|c|}
\hline \multicolumn{1}{|c|}{ Показатель } & 2004 & 2005 & 2006 & 2007 & 2008 & 2009 & 2010 & 2011 & 2012 & 2013 & 2014 \\
\hline $\begin{array}{l}\text { Интегральный социальный } \\
\text { процесс }\end{array}$ & $\mathrm{C}$ & $\mathrm{C}$ & $\mathrm{H}$ & $\mathrm{H}$ & $\mathrm{C}$ & $\mathrm{C}$ & $\mathrm{C}$ & $\mathrm{H}$ & $\mathrm{H}$ & $\mathrm{H}$ & $\mathrm{C}$ \\
\hline
\end{tabular}

Н - низкий уровень; C - средний уровень; В - высокий уровень.

Как показывают расчеты, уровень социального благосостояния изменяется в диапазоне «средний - низкий». При этом динамику изменений данного показателя можно интерпретировать как социальную деградацию. Нестабильность процессов, проявляющаяся в высоком уровне флуктуаций, не позволяет изменить динамику интегрального социального процесса, отражающего уровень регионального благосостояния. Кроме того, уровень результативности интегрального социального процесса во многом зависит от результативности процессов, разворачивающихся в экономике края. В данном случае низкий уровень развития социальной сферы яв-

\section{Baikal Research Journal}

электронный научный журнал Байкальского государственного университета 
ляется следствием стагнации интегрального экономического процесса. Выявленные тенденции изменения результативности процессов, протекающих в экономической и социальной сфере, обусловили особенности формирования благосостояния в Забайкальском крае (рис.).

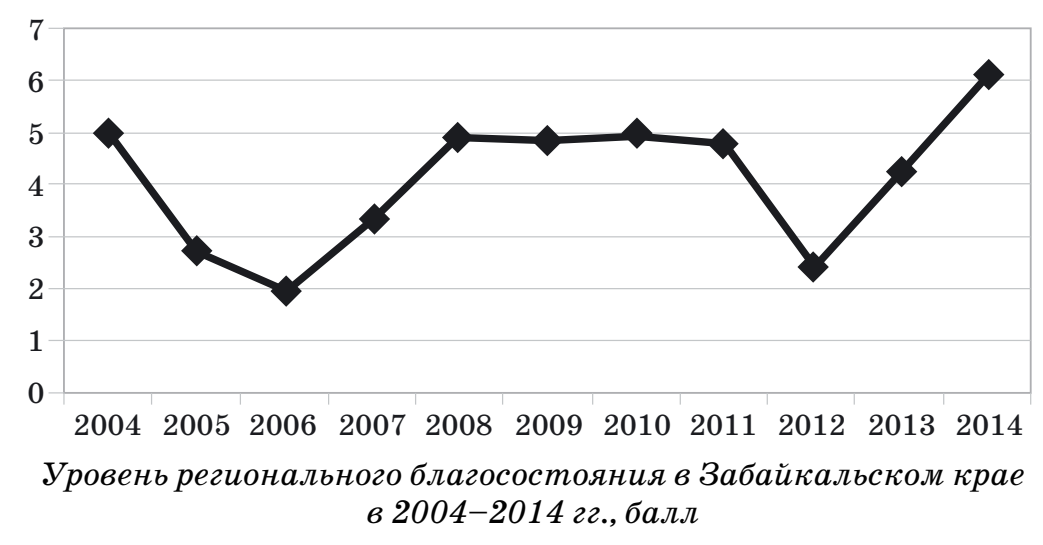

Высокая волатильность данного показателя может интерпретироваться как зависимость благосостояния в Забайкальском крае от внешних факторов, а также свидетельствовать об отсутствии в крае адекватной политики противостояния вызовам внешней среды. Характер изменений в уровне регионального благосостояния свидетельствует о периодическом возникновении в крае серьезных проблем с обеспечением минимально приемлемого для жизнедеятельности уровня жизни. Достигнутый в крае уровень благосостояния не позволяет аккумулировать ресурсы и создавать потенциал развития в регионе. В свою очередь, отсутствие собственных ресурсов развития обусловливает периодическое возникновение данных проблем. Сложившийся уровень благосостояния обусловлен системным взаимодействием элементов экономической и социальной сфер. Анализ показывает, что наиболее слабым элементом в данной системе является социальная сфера, в которой отмечается значительная «проблемная зона», сформированная процессами, нацеленными на удовлетворение потребностей в труде, культуре, информации. В то же время именно в социальной сфере имеются наибольшие резервы для повышения уровня благосостояния, которые можно использовать за счет перераспределения ресурсов между процессами, формирующими блага, и процессами, создающими препятствия для их потребления. При этом следует особо подчеркнуть, что оптимизация ресурсов в социальной сфере не означает сокращения ресурсов входа в процессор, а, наоборот, их увеличение, за счет сокращения использования ресурсов на устранение барьеров и проблем, которые создаются такими процессами.

Таким образом, анализ благосостояния в Забайкальском крае позволяет сделать следующие выводы:

1. Уровень благосостояния в Забайкальском крае обусловливает депрессивный характер социально-экономического развития региона.

2. Уровень экономического благосостояния является результатом стагнации процессов в экономической сфере.

3. Уровень социального благосостояния не отвечает тенденциям и требованиям развития современного общества. Динамика уровня социального благосостояния, а также анализ удовлетворения наиболее важных социальных потребностей населения свидетельствуют о формировании тенденций социально-культурной деградации населения Забайкальского края.

\section{Baikal Research Journal}


4. Вместе с тем в крае имеются резервы для повышения уровня благосостояния, которые связаны с оптимизацией процессов как в социальной, так и в экономической сферах, направленной на сокращение процессов, тормозящих темпы роста благосостояния, а также за счет сокращения ресурсов входа, поступающих к процессам, создающим определенные социальные проблемы.

\section{Список использованной литературы}

1. Акопов В. Национальная и региональная модели благосостояния / В. Акопов, Ю. Гаджиев // Общество и экономика. - 2002. - № 6. - С. 120-139.

2. Экономический рост и подъем народного благосостояния / Е. Г. Антосенков, Г. Кряжев, Н. П. Кузнецова [и др.] ; под ред. Е. Г. Антосенкова. - М. : Экономика, 1987. - 206 с.

3. Беломестнов В. Г. Потенциал экономического роста регионов : монография / В. Г. Беломестнов, А. А. Унгаев, В. А. Рубан. - Улан-Удэ : Изд-во Вост.-Сиб. гос. уни-т технологий и управления, 2011. - 271 с.

4. Берштейн Л. С. Использование нечеткого дедуктивного вывода в системах управления [Электронный ресурс] / Л. С. Берштейн, А. В. Боженюк // Перспективные информационные технологии и интеллектуальные системы. - 2001. - № 3 (7). - Режим доступа : http:// pitis.tsure.ru/.

5. Бияков О. А. Теория экономического пространства: методологический и региональный аспект / О. А. Бияков. - Томск : Изд-во Том. ун-та, 2004. - 158 с.

6. Потребности, доходы, потребление. Методология анализа и прогнозирования народного благосостояния / отв. ред. Н. П. Федоренко, Н. М. Римашевская. - М. : Наука, 1979. - $240 \mathrm{c}$.

7. Самаруха В. И. Критериальные подходы к оценке социально-экономической эффективности региона / В. И. Самаруха, Т. Г. Краснова, Т. Н. Плотникова // Известия Иркутской государственной экономической академии. - 2005. — № 1 (42). - С. 46-49.

8. Самаруха В. И. Формирование конкурентных преимуществ регионов. // В. И. Самаруха, Т. Г. Краснова // Известия Иркутской государственной экономической академии. 2008. - № 4 (60). - С. 26-29.

9. Сангадиева И. Г. Стратегическое управление региональными социально-экономическими системами / И. Г. Сангадиева // Известия Иркутской государственной экономической академии. - 2005. - № 1 (42). - С. 56-60.

\section{References}

1. Akopov V., Gadzhiyev Yu. National and regional models of welfre. Obshchestvo $i$ ekonomika = Science and Economy, 2002, no. 6, pp. 120-139. (In Russian).

2. Antosenkov E. G., Kryazhev G., Kuznetsova N. P. Ekonomicheskii rost i pod»em narodnogo blagosostoyaniya [Economic growth and recovery of national welfare]. Moscow, Ekonomika Publ., 1987. 206 p.

3. Belomestnov V. G., Ungayev A. A., Ruban V. A. Potentsial ekonomicheskogo rosta regionov [Potential of regional economic growth]. Ulan-Ude, East Siberia State University of Technology and Management Publ., 2011. 271 p.

4. Bershtein L. S., Bozhenyuk A. V. Use of indistinct deductive conclusion in management systems. Perspektivnye informatsionnye tekhnologii i intellektual'nye sistemy = Advanced Information Technologies an Intellectual systems, 2001, no. 3 (7). Available at: http:// pitis.tsure. $\mathrm{ru}$. (In Russian).

5. Biyakov O. A. Teoriya ekonomicheskogo prostranstva: metodologicheskii i regional'nyi aspekt [Theory of economic space: methodological and regional aspect]. Tomsk State University Publ., 2004. $158 \mathrm{p}$.

6. Fedorenko N. P., Rimashevskaya N. M. (ed.). Potrebnosti, dokhody, potreblenie. Metodologiya analiza i prognozirovaniya narodnogo blagosostoyaniya [Needs, incomes, consumption. Methodology of analysis and forecasting of national welfare]. Moscow, Nauka Publ., 1979. 240 p.

7. Samarukha V. I., Krasnova T. G., Plotnikova T. N. Criteria approaches to estimation of regional social and economic efficiency. Izvestiya Irkutskoi gosudarstvennoi ekonomicheskoi aka demii = Bulletin of Irkutsk State Economics Academy, 2005, no. 1 (42), pp. 46-49. (In Russian).

\section{Baikal Research Journal}


8. Samarukha V. I., Krasnova T. G. Formation of competitive advantages of regions. Izvestiya Irkutskoi gosudarstvennoi ekonomicheskoi akademii = Bulletin of Irkutsk State Economics Academy, 2008, no. 4 (60), pp. 26-29. (In Russian).

9. Sangadieva I. G. Strategic management of the regional social economic systems. Izvestiya Irkutskoi gosudarstvennoi ekonomicheskoi akademii = Bulletin of Irkutsk State Economics Academy, 2005, no. 1 (42), pp. 56-60. (In Russian).

\section{Информация об авторе}

Ковальчук Людлила Борисовна - кандидат экономических наук, доцент, кафедра мировой экономики, Читинский институт, Байкальский государственный университет, 672000 , г. Чита, ул. Анохина, 56, e-mail: kovalchuklb@mail.ru.

\section{Author}

Ludmila B. Kovalchuk - PhD in Economics, Associate Professor, Chair of World Economics, Chita Institute, Baikal State University, 56 Anokhin St., 672000, Chita, Russian Federation; e-mail: kovalchuklb@mail.ru.

\section{Библиографическое описание статьи}

Ковальчук Л. Б. Анализ уровня благосостояния в Забайкальском крае / Л. Б. Ковальчук // Baikal Research Journal. — 2016. — T. 7, № 4. — DOI : 10.17150/2411-6262.2016.7(4).13.

\section{Reference to article}

Kovalchuk L. B. Analysis of welfare level in Zabaikalsky Territory. Baikal Research Journal, 2016, vol. 7, no. 4. DOI : 10.17150/2411-6262.2016.7(4).13. (In Russian).

\section{Baikal Research Journal}

